\title{
A novel constructed SPT15 mutagenesis library of Saccharomyces cerevisiae by using gTME technique for enhanced ethanol production
}

\author{
Ashraf A. M. M. El-Rotail ${ }^{1,2}$, Liang Zhang ${ }^{1}$, Youran Li', Shuang Ping Liu ${ }^{1}$ and Gui Yang Shi ${ }^{*}$
}

\begin{abstract}
During the last few years, the global transcription machinery engineering (gTME) technique has gained more attention as an effective approach for the construction of novel mutants. Genetic strategies (molecular biology methods) were utilized to get mutational for both genes (SPT15 and TAF23) basically existed in the Saccharomyces cerevisiae genome via screening the gTME approach in order to obtain a new mutant S. cerevisiae diploid strain. The vector pYX212 was utilized to transform these genes into the control diploid strain S. cerevisiae through the process of mating between haploids control strains S. cerevisiae (MAT-a [CICC 1374]) and (MAT-a [CICC 31144]), by using the oligonucleotide primers SPT15-ECoRI-FW/SPT15-Sall-RV and TAF23-Sall-FW/TAF23-Nhel-RV, respectively. The resultant mutants were examined for a series of stability tests. This study showed how strong the effect of using strategic gTME with the importance of the modification we conducted in Error Prone PCR protocol by increasing $\mathrm{MnCl}_{2}$ concentration instead of $\mathrm{MgCl}_{2}$. More than ninety mutants we obtained in this study were distinguished by a high level production of bioethanol as compared to the diploid control strain.
\end{abstract}

Keywords: Bioethanol, Error-prone PCR, Ethanol production, Ethanol tolerance, Global transcription machinery engineering, SPT15

\section{Introduction}

Ethanol (ETOH) is a colorless liquid produced by the fermentation of sugars by a variety of microbes such as Saccharomyces cerevisiae (S. cerevisiae), Escherichia coli (E. coli), Klebsiella oxytoca and Zymomonas mobilis (Tan et al. 2016). It is used as fuel, solvent, sterilizer, antiseptic for wounds, cosmetics and pharmaceutical industry. S. cerevisiae has been studied extensively as a model organism among eukaryotes (Botstein and Fink 1988). The requirements of $S$. cerevisiae to produce a high level of ethanol are its ability to withstand an elevated

\footnotetext{
*Correspondence: gyshi@jiangnan.edu.cn; 2100761902@qq.com ${ }^{1}$ The Key Laboratory of Industrial Biotechnology, Ministry of Education, National Engineering Laboratory for Cereal Fermentation Technology, School of Biotechnology, Jiangnan University, 1800 Lihu Road, Wuxi 214122, Jiangsu, China

Full list of author information is available at the end of the article
}

concentration of ethanol and sugar existed in the fermentation medium (Hou 2009).

Recently, the global transcription machinery engineering (gTME) has been applied as an effective technique to enhance the target specific phenotype of microbes (Alper et al. 2006). The gTME uses molecular biology methods such as Error-prone polymerase chain reaction (Ep-PCR), DNA shuffling, etc. to construct an initial transcription factor and screen the target phenotype to obtain the enhanced metabolic flux or bacteria with a specific phenotype. Ep-PCR is a fast and cheap molecular biology method for random mutation in a particular piece of DNA. This technique is a based on PCR and its reaction mixture composition. Upon replication in EPPCR, Taq polymerase is modulated by alteration of the composition of the reaction buffer usually by adjusting $\mathrm{Mg}$ and $\mathrm{Mn}$ ions as well as dNTPs in the PCR reaction. In this condition, the Taq polymerase, which lack DNA 
proof-reading property, introduces errors in a newly synthesized DNA during base pairing. The control of PCR reaction composition regulates the frequency of misincorporation of nucleotide bases into the sequence. In some directed evolution experiments, a high number of mutations around $9-12 \mathrm{bp} / \mathrm{kb}$ may be obtained (Cadwell and Joyce 1992). Therefore, cloning of the resulted PCR fragment or screened libraries of mutants provide proteins with desired activity (McCullum et al. 2010; Drummond et al. 2005). It produces most of the functional genes; however RNA polymerase II transcription efficiency is determined by initiation of transcription factors and promoter binding protein, and one of the first transcription factors in S. cerevisiae is TATA-binding protein (TBP). The SPT15 regulates the expression of most of all those genes, and essentially its variants modulate many genes those are necessary for ethanol tolerance. Previous research showed that variants of the $S$. cerevisiae TBP SPT15 could improve the yield of ethanol (Tan et al. 2016) by using the gTME (Alper et al. 2006).

The protocols established by (Cadwell and Joyce 1992; Alper et al. 2006) were adopted on our study with some modification in the process of polymerase chain reaction (PCR) protocol. Different concentrations of $\mathrm{MnCl}_{2}$ were used instead of $\mathrm{MgCl}_{2}$ to produce mutations in the sequence of SPT15 and TAF23 genes by using the EpPCR amplification process. This approach was satisfactorily applied to get mutants by which it would be able to improve ethanol production and ethanol tolerance.

\section{Materials and methods}

\section{Microbial strains and culture media}

Escherichia coli JM109 was used as a host for plasmid construction. It was grown in Luria-Bertani (LB) medium containing $5 \mathrm{~g} / \mathrm{L}$ yeast extract, $10 \mathrm{~g} / \mathrm{L}$
Bacto-peptone and $10 \mathrm{~g} / \mathrm{L}(\mathrm{NaCl})$ and cultured at $37^{\circ} \mathrm{C}$. Super optimal broth (SOB) containing $5 \mathrm{~g} / \mathrm{L}$ yeast extract, $20 \mathrm{~g} / \mathrm{L}$ Bacto-peptone, $0.95 \mathrm{~g} / \mathrm{L}\left(\mathrm{MgCl}_{2}\right), 0.186 \mathrm{~g} / \mathrm{L}(\mathrm{KCl})$ and $0.5 \mathrm{~g} / \mathrm{L}(\mathrm{NaCl})$ was used before spreading on solid media after transformation. S. cerevisiae strain was used for genetic manipulation and cultured in Basic mediumBacto-peptone glucose broth (YPD) medium; this medium was used for routine growth of yeast strains at $30{ }^{\circ} \mathrm{C}$ and contained $10 \mathrm{~g} / \mathrm{L}$ yeast extract, $20 \mathrm{~g} / \mathrm{L}$ Bactopeptone and $20 \mathrm{~g} / \mathrm{L}$ glucose. Solid media contained $2 \%$ agar for both types of mediums. Respective antibiotics [ampicillin (Amp) $100 \mathrm{mg} / \mathrm{L}$; kanamycin (Kan) $35 \mathrm{mg} / \mathrm{L}$ ] were added to maintain the plasmids (Liu et al. 2014). For screening, the medium (YPDG) containing $10 \mathrm{~g} / \mathrm{L}$ yeast extract, $20 \mathrm{~g} / \mathrm{L}$ Bacto-peptone, $20 \mathrm{~g} / \mathrm{L}$ glucose and resistance gene Glycosid-418 (G418) that used with the final concentrations ( 250 and $350 \mu \mathrm{g} / \mathrm{mL}$ ), respectively (Wang et al. 2004). The Fermentation medium (YPDT) was contained $10 \mathrm{~g} / \mathrm{L}$ yeast extract, $20 \mathrm{~g} / \mathrm{L}$ Bacto-peptone, $20 \mathrm{~g} / \mathrm{L}$ glucose and $0.2 \mathrm{~g} / \mathrm{L}$ Thiamine.

\section{Genetic manipulation strain}

Saccharomyces cerevisiae eukaryotic system containing the non-mutant genes chromosomal copy of SPT15 and TAF23 genes was selected. Table 1 shows that two haploids types of industrial ethanol-producing yeast $(M A T-\mathrm{a} / M A T-\alpha)$ were mated and genetically manipulated in this study, as well Table 2 shows that oligonucleotide primers (MAT-F), (MAT-a) and (MAT-alpha) were used in order to obtain a strain possessing diploid genetic traits, named as S. cerevisiae R-control. The protocol of Hoffman and Winston (1987) was used to extract genomic DNA (gDNA) with slight modifications by using Mini-DNA fragment Rapid Kit (BioSCi Biotech Co., LTD, Hangzhou, China).

Table 1 Microbial strains and plasmids used

\begin{tabular}{|c|c|c|}
\hline Strains/plasmids & Relevant characteristics & Source of reference \\
\hline \multicolumn{3}{|l|}{ Strains } \\
\hline $\begin{array}{l}\text { S. cerevisiae haploid } \\
\text { strain }\end{array}$ & Wild-type (MAT- a) CICC 1374 & China center of industrial culture collection (CICC) \\
\hline $\begin{array}{l}\text { S. cerevisiae haploid } \\
\text { strain }\end{array}$ & Wild-type (MAT- a) CICC 31144 & \\
\hline S. cerevisiae R-control & Diploid strain & This study \\
\hline E. coli JM109 & $\begin{array}{l}\text { recA1 supE44 endA1 hsdR17 gyrA96 relA1 thi (Lac-proAB) F'[traD36 proAB }{ }^{+} \\
\text {lac19 lacZM15] }\end{array}$ & Stratagene \\
\hline \multicolumn{3}{|l|}{ Plasmids } \\
\hline pMD19-T vector & Amp $p^{r}$ clone vector & TaKaRa, Japan \\
\hline pYX212 & Amp ${ }^{r} \mathrm{TPI}$ promoter & This study \\
\hline pYX212-kan-SPT15-Mu & pYX212 with SPT15 mutant gene & This study \\
\hline pYX212-kan-TAF23-Mu & pYX212 with TAF23 mutant gene & This study \\
\hline
\end{tabular}


Table 2 The oligonucleotide primers used

\begin{tabular}{ll}
\hline Primer names & Sequence $\left(\mathbf{5}^{\prime} \mathbf{- 3}^{\prime}\right)^{\mathbf{a}}$ \\
\hline SPT15-ECORI-FW & CCGGAATTCATGGCCGATGAGGAACGTTTAAAGG \\
SPT15-Sall-RV & CGCTAGGTCGACTCACATTTTTCTAAATTCACTTAG- \\
& CACA \\
TAF23-Nhel-RV & ACTCGAGCTAGCCTAACGATAAAAGTCTGGGCGACCT \\
TAF23-Sall-FW & CGCTAGGTCGACATGGATTTTGAGGAAGATTACGAT \\
pYX212-FW & GGGCAGCATAATTTAGGAG \\
pYX212-RV & AGGGATGTAT CGGTCAGTCA \\
425-TT-BamHI-FW & CGCGGATCCATCCGTATGATGTGCCTGACTA \\
426-TT-ECORV-RV & AATAAGATATCAGGGAAGAAAGCGAAAGGAG \\
(MAT-F) $F$ & AGTCACATCAAGATCGTTATGG \\
(MAT-a) & ACTCCACTTCAAGTAAGAGTTTG \\
(MAT-alpha) & GCACGGAATATGGGACTACTTCG
\end{tabular}

a Restriction sites are in italic and underlined

\section{Target genes}

TATA-binding protein subunit of transcription factor complexes Transcription factor II D (TFIID) and Transcription factor II B (TFIIB) were used (Cormack and Struhl 1992). It plays an enormous role during gene expression in yeast cells (Hampsey 1998). Additionally, much gene regulation takes place by targeting TBP with coactivators and corepressors, which interact with TBP for gene transcription (Lewis and Reinberg 2003). Mutations in the TBP confer enhanced tolerance to stress in $S$. cerevisiae of ethanol and glucose (Lee and Young 1998). The SPT15 and TAF23 were used in this study to improve cellular phenotype for yeast strain with ethanol tolerance. Both genes express via transcription during RNA polymerase II coupled with the association of TBP with general transcription factors and regulators (Alper and Stephanopoulos 2007; Gietz and Woods 2006; Jungwoo et al. 2011).

\section{Extraction, cloning and overexpression of the target genes}

The extracted amount of gDNA was used as a template with sequence-specific primers mentioned below in Table 2 to begin the process of cloning of SPT15 and TAF23 genes in this study. Standard methods were used for PCR amplification, analysis of DNA fragments and electroporation as directed by Green and Sambrook (2012). The extension reaction was adjusted on $72{ }^{\circ} \mathrm{C}$ for $10 \mathrm{~min}$. In addition to, the annealing temperature was changed it to $58,55^{\circ} \mathrm{C}$ for SPT15 and TAF 23 genes, respectively. The PCR and Ep-PCR experiments were performed by using the Real-Time PCR Detection System with software CFX Manager 3.0 (Bio-Rad, USA), using rTaq DNA polymerase (TaKaRa, Japan). All PCR products were sequenced to verify the mutation rate for all the new mutations and to get the mutant genes sequence for SPT15-Mu and TAF23-Mu.
This was followed by cloning and transformation and then plated the ligation product on specific antibioticcontaining medium. The plasmid(s) and gene(s) verification was done by Sangon Biotech CO., LTD, Shanghai, China.

\section{Design of primers and vectors Plasmid design with target genes}

The oligonucleotide primers SPT15-EcoRI-FW/ SPT15-SalI-RV and TAF23-SalI-FW/TAF23-NheI-RV were designed as primers for SPT15 and TAF23 genes, respectively. The genome sequence of $S$. cerevisiae and both genes sequences were searched using the $S$. cerevisiae Genome Database and the National Center for Biotechnology Information. All the target genes were PCR amplified from the gDNA of $S$. cerevisiae R-control as a template using oligonucleotide primers SPT15-EcoRIFW/SPT15-SalI-RV and TAF23-SalI-FW/TAF23-NheI$\mathrm{RV}$, respectively as referred in Table 2 . The resulting PCR products were purified by Mini-DNA fragment Rapid Kit and the target genes were ligated with vector (pYX212) which formed two plasmids pYX212-Amp-SPT15 and pYX212-Amp-TAF23. Both plasmids were individually transformed into E. coli JM109 competent cells for multiplication on SOB medium with Amp $(100 \mu \mathrm{g} / \mathrm{mL})$ at $37{ }^{\circ} \mathrm{C}$ for $24 \mathrm{~h}$. Then, these plasmids (pYX212-AmpSPT15 and pYX212-Amp-TAF23) were extracted and purified by using a Plasmid Mini-Preps Kit (BioSCi Biotech Co., LTD, Hangzhou, China). These genes obtained from the previous step were used as a template to initiate DNA amplification using Ep-PCR technique for the next steps and preserved in pMD19-T vector.

\section{Plasmid design with mutant genes}

The pYX212-TPI plasmid was designed as an expression vector; designed as bacterial and yeast expressing system. For this plasmid, the prokaryotic and eukaryotic selection markers are Amp, uracil and Kan as shown in Fig. 1. Oligonucleotide primers were designed based on the pYX212 vector, with restriction sites EcoRI and SalI for SPT15 gene mutagenesis; moreover SalI and NheI were used for TAF23. For plasmid construction, overexpression of genes and electroporation, standard methods were applied as directed (Green and Sambrook 2012; Lee et al. 2007) (Table 2).

Both SPT15 and TAF23 genes were randomly mutated, amplified by standard PCR and ligated individually with pYX212 plasmid. The fragment of SPT15 mutant gene and PYX212 plasmid were digested with EcoRI and SalI, however the pYX212 plasmid and TAF23 gene were digested by using restriction enzymes SalI/NheI and ligated by using T4 DNA Ligase (Thermo Scientific CO., LTD, Meridian, USA) to get pYX212-kan-SPT15-Mutant 


\section{a}

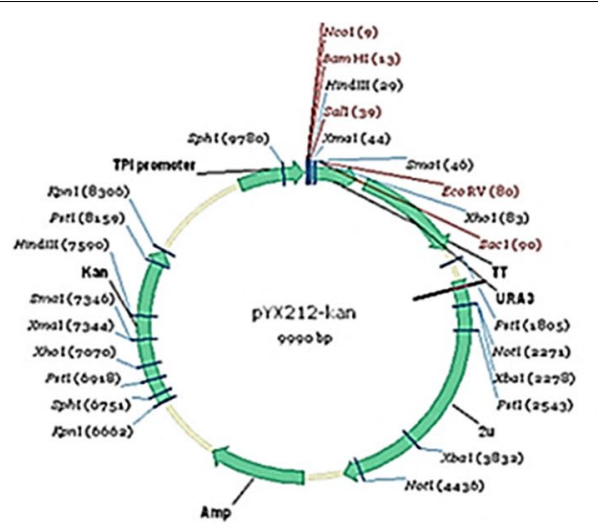

b

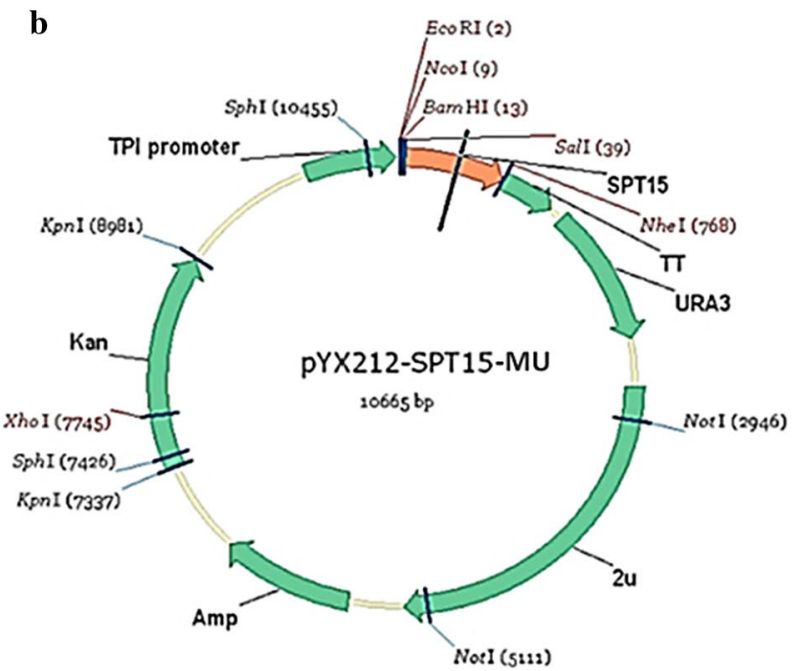

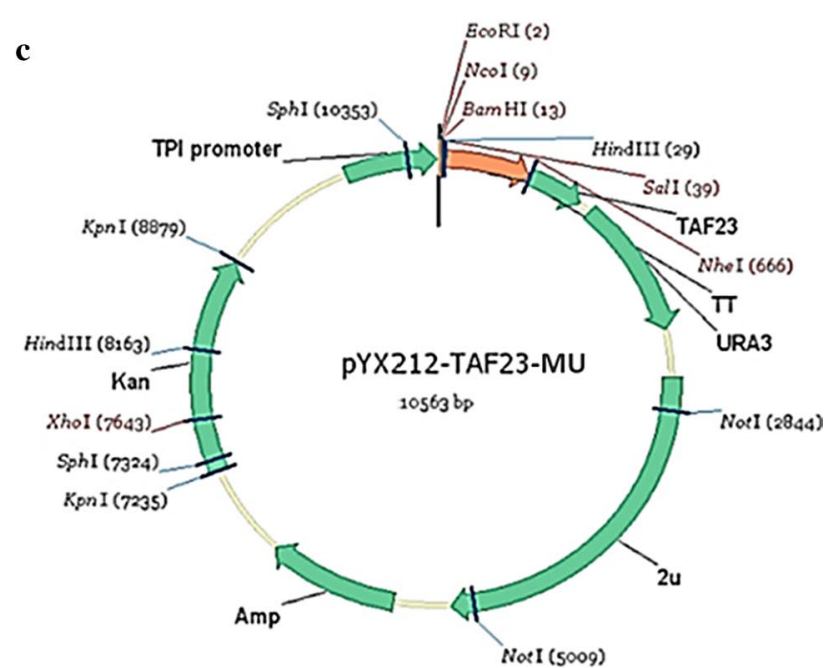

c

Fig. 1 The physical maps of recombinant plasmids. a The pYX212-kan (empty vector). b. cThe pYX212 with SPT15-Mu and TAF23-Mu, respectively. The genes are under the R-control of TPI promoter and terminator with ECORI and Sall restriction sites for SPT15 and Sall and Nhel restriction sites for TAF23; (Ampr) ampicillin resistance gene; (Kan') Kanamycin resistance gene; (G418) resistance gene

(pYX212-kan-SPT15-Mu) and pYX212-kan-TAF23Mutant (pYX212-kan-TAF23-Mu) plasmids, respectively.

\section{Construction of mutant genes libraries}

The gTME strategy and Ep-PCR were used to express SPT15 and TAF23 genes encoding TBP. They are commonly used method to give the irregular variations of mutations into a defined segment and specific of the DNA (Hou et al. 2015). Those approaches are based on the amplification of the entire gene(s) using primers that possess the region of interest (Hemsley et al. 1989). Those techniques were used to create randomized genomic libraries by working on the principle $r$-Taq polymerase that can anneal incompatible base pairs (bp) during PCR (Drummond et al. 2005; McCullum et al. 2010). The latter produced the largest possible number of changes in the gene sequence (low, medium and high) with strong and stable rate of mutation(s). The procedure was adjusted by adding $1-30 \mu \mathrm{L}$ of $\mathrm{MnCl}_{2}(5 \mathrm{mM})$, and mixed with
dNTPs one by one and retain $22 \mu \mathrm{L}$ of $\mathrm{MgCl}_{2}(25 \mathrm{mM})$ within $100 \mu \mathrm{L}$ Ep-PCR reaction mixture.

Accordingly, this modification allowed initiating DNA amplification beginning with small amounts of original molecule to bring to considerable amounts of a high random mutagenesis. Then, the library of mutations was constructed with that combination of genes SPT15-Mu and TAF23-Mu. The aforesaid mutations were inserted into the strain by using PYX212 vector. The new mutations could induce the production of ethanol at high rate which is expected to be higher than the R-control strain.

The mutagenic reaction mixture contained different amount of $\mathrm{MnCl}_{2}(1,3,5,10,20$ and $30 \mu \mathrm{L})(5 \mathrm{mM})$, $22 \mu \mathrm{L}$ of $\mathrm{MgCl}_{2}(25 \mathrm{mM}), 10 \mu \mathrm{L}$ of $(10 \times$ Taq Buffer $), 1 \mu \mathrm{L}$ (each) PCR primers (mentioned above in Table 2), $1 \mu \mathrm{L}$ of Template gDNA, $1 \mu \mathrm{L}$ rTaq DNA polymerase, $10 \mu \mathrm{L}$ of $(10 \times$ dNTP Mix), then fulfill the volume mixture to $100 \mu \mathrm{L}$ of distilled water. The $(10 \times$ dNTP Mix $)$ mixture was prepared by using an equal dNTP concentrations as 
follows: $2 \mu \mathrm{L}$ of dATP $(0.2 \mathrm{mM}), 2 \mu \mathrm{L}$ of dGTP $(0.2 \mathrm{mM})$, $10 \mu \mathrm{L} \mathrm{dCTP}(1 \mathrm{mM}), 10 \mu \mathrm{L}$ dTTP $(1 \mathrm{mM})$ and the distilled water was added until the volume of $100 \mu \mathrm{L}$. The dGTP, dNTP, dCTP, dTTP, and rTaq DNA polymerase enzymes were purchased from TaKaRa, Japan.

\section{Transformation for SPT15-Mu and TAF23-Mu genes into $S$. cerevisiae}

High-efficiency yeast transformation procedure was determined according to the methods of Gietz (2014) and Gietz and Woods (2006), with some modifications. Briefly, each $50 \mu \mathrm{L}$ plasmid harboring DNA mutant gene was added individually to a tube. Then the mixture was filled up to $380 \mu \mathrm{L}$ alongside by using transformation mixture [240 $\mu \mathrm{L}$ PEG (50\%), $36 \mu \mathrm{L}$ LiAc $(1 \mathrm{M}), 50 \mu \mathrm{L}$ ssDNA $(2 \mathrm{mg} / \mathrm{mL}), 54 \mu \mathrm{L}$ sterile distilled water]. total mixture was subsequently heated shockingly at $42{ }^{\circ} \mathrm{C}$ for $25 \mathrm{~min}$. Cells were harvested by centrifugation at $2.4 \mathrm{~g}$ for $2 \mathrm{~min}$ at room temperature, re-suspended in $1 \mathrm{~mL}$ sterile water, then mixed by inverting the tube up and down. $100 \mu \mathrm{L}$ of the suspension was plated on agar medium containing G418 $(100 \mu \mathrm{g} / \mathrm{mL})$. The plates were incubated at $30^{\circ} \mathrm{C}$ for 2 days for growth.

\section{Study of mutations characteristics Mutations stability}

Ten colonies were selected for the screening as a random mutation. In order to ensure the stability test of each colony, $100 \mu \mathrm{L}$ was plated on YPD solid medium in triplicate with different concentration of Kan. The colony that has a good viability among the grown colonies was then transferred on YPD containing G418 $(250 \mu \mathrm{g} / \mathrm{mL})$ and incubated at $30{ }^{\circ} \mathrm{C}$ until single colonies appeared. By the unaided eye, the best five colonies were picked up after photographed the plates. Subsequently, re-grown on a fresh YPDG medium containing G418 $(350 \mu \mathrm{g} / \mathrm{mL})$; then incubated at $30{ }^{\circ} \mathrm{C}$ for 2 days. Afterward, the resistant colonies were streaked out (Guo et al. 2011; Zhang et al. 2011). Finally, colony PCR reaction was performed to verify the success of the mutations by using oligonucleotide primers 425-TT-BamHI-FW/426TT-EcoRV-RV as referred in Table 2. The PCR products were loaded on 1.5\% Agarose and visualized to make sure the criteria of the stab le genes selection.

\section{Ethanol tolerance of mutant strains}

Ethanol tolerance test was used in order to assay the ability of the 102 mutations that harboring SPT15 genes. It was carried out by spot assay in duplicate onto YPD plates containing Kan within various concentrations of ethanol 1, 3, 5, 7, 10 and $15 \%(\mathrm{v} / \mathrm{v})$, respectively. The colonies forming ability and viability on a high level of ethanol were monitored after incubation at $30{ }^{\circ} \mathrm{C}$ for 3 days (Kasavi et al. 2014).

\section{Effect of ethanol concentration on the growth rate of mutant strains}

The ethanol tolerance of the SPT15 mutants and S. cerevisiae R-control strains were grown in 24 deep holes microplate containing $5 \mathrm{~mL}$ YPD medium in the absence of ethanol in each hole, as a primary pre-culture to grow the strains. The $\mathrm{OD}_{595}$ was reached 0.05 , then $40 \mu \mathrm{L}$ of the pre-cultures from SPT15 mutants and R-control strain were inoculated into 24 deep holes microplate containing $3 \mathrm{~mL}$ liquid fresh medium present/absent of G418 $(250 \mu \mathrm{g} / \mathrm{mL})$. In this estimation, five various concentration of ethanol $0,1,3,5$ and $7 \%(\mathrm{v} / \mathrm{v})$ were used for each treatment. Finally, mutants and R-control strain growth rate were monitored by measuring dry cell weight $(\mathrm{DCW})$ and $\mathrm{OD}_{595}$ values. Microplate reader (EZ Read 800, Biochrom Ltd., Cambridge, UK), with Galapagos Exert Software (Version 1.1) were used to recording $\mathrm{OD}_{595}$ values.

\section{Measurement of the ethanol and glucose yield Fermentation conditions}

Fermentation was carried out in the cap-covered flasks $(500 \mathrm{~mL})$ containing $50 \mathrm{~mL}$ YPDT medium as followed: $20 \mathrm{~g} / \mathrm{L}$ glucose, $10 \mathrm{~g} / \mathrm{L}$ yeast extract, $20 \mathrm{~g} / \mathrm{L}$ Bacto-peptone and $0.2 \mathrm{~g} / \mathrm{L}$ thiamine (vitamin B1) (Kotarska et al. 2006; Xu et al. 2012), and $5 \mathrm{~mL}$ of inoculum were added. The mixture was cultured at $30^{\circ} \mathrm{C}$ and $200 \mathrm{rpm}$ till $\mathrm{OD}_{595}$ reached 1 .

\section{High performance liquid chromatography analysis}

The broth samples were centrifuged at $1 g$ for $20 \mathrm{~min}$ then filtered through a $0.22 \mu \mathrm{m}$ filter (Whatman ${ }^{\circledR}$ Spar$\tan ^{\circledR}$ HPLC certified syringe filters, sterile, diam. $13 \mathrm{~mm}$ ). The supernatant was appropriately diluted by $10 \%$ of Trichloro acetic acid (TDA) (1:1) for the product analysis. The concentrations of the samples were estimated by high performance liquid chromatography (HPLC) analysis, with a Shodex RI SUGER SH-1011 HPLC column $(7 \mu \mathrm{m}, 8$ I.D. $\times 300 \mathrm{~mm}$ ) (Showa Denko Co., Ltd., K.K., Japan). The column temperature was heated at $50{ }^{\circ} \mathrm{C}$ with $0.01 \mathrm{M} \mathrm{H}_{2} \mathrm{SO}_{4}$ as a mobile phase and flow rate was $0.8 \mathrm{~mL} / \mathrm{min}$. The concentrations were subsequently detected with a refractive index detector with $285 \mathrm{~nm}$ wave length (HITACHI High Technologies Co., Ltd., Tokyo, Japan) Model (CM 5110/5210/5310/5430/5450) to estimate the percentage of both glucose and ethanol in the samples. The HPLC analysis was performed by isocratic condition using $1 \%$ Sulfuric acid in water $(\mathrm{v} / \mathrm{v})$ as mobile phase. The product was eluted around $22 \mathrm{~min}$ for total running time per sample. All HPLC data were analyzed with EZChrom Elite (Version 3.3.2) SP2 Chromatography Data System, Agilent Tech software. The percentage of the ethanol yield production between the 
mutant strains and R-control strain was estimated by using the following equation:

$$
I R=\left[\left(E P_{2} / E P_{1}\right) * 100\right]-100
$$

IR increase of rate, $\mathrm{EP}_{1}$ : ethanol production for mutant strains, $\mathrm{EP}_{2}$ : ethanol production for R-control strain.

\section{Results}

\section{Hybridization, amplification and construction of plasmid}

The colonies were chosen for mating process between the haploid strains of S. cerevisiae (MAT-a and MAT- $\alpha$ ) for the industrial ethanol-producing yeast. Conjunction process resulted a strain of $S$. cerevisiae possessing diploid genetic traits, and was named S. cerevisiae R-control. The gDNA of $S$. cerevisiae R-control was used as a template for PCR reaction. The clear bands of 723 and $621 \mathrm{bp}$ for SPT15 and TAF23 genes, respectively were identified. Construction and ligation of plasmid with genes have resulted in clear bands at 3323 and 3221 bp for pMD19T-Amp-SPT15 and pMD19-T-Amp-TAF23, respectively.

\section{Construction of mutant genes libraries}

The Ep-PCR was applied using different concentrations of $\mathrm{MnCl}_{2}$ (1, 3, 10 and 20\%) for the alteration of each gene sequence, and 150 mutants were obtained. Based on the highest rate of success in the mutation, 50 mutants were chosen for SPT15 and 6 mutants for TAF23. The chosen mutants were classified into three categories; (high, medium and low) based on the error rate (MER) according to the classification previously reported by Lanza and Alper (2011). Regarding the SPT15 gene, 27 mutant strains were identified as medium MER and 23 mutant strains as high MER. In contrast, 6 mutant strains as low MER were detected with TAF23 (Fig. 2a, b). All the strains have high similarity with the R-control strain which is at least $>75 \%$.

In details, by using $1 \%$ of $\mathrm{MnCl}_{2}, 1$ and 3 mutants with a medium and high MER, respectively were observed with SPT15; however 3 mutants with a low MER were observed with TAF23. Moreover, $3 \%$ of $\mathrm{MnCl}_{2}$ resulted in the construction of 5 and 9 mutants with a high and medium MER, respectively with SPT15. However 3 mutants with a low MER were constructed with TAF23 using the same concentration. Furthermore, 14 mutant strains with a high MER and 2 mutant strains with a medium MER were formed by using $10 \%$ of $\mathrm{MnCl}_{2}$ with SPT15. Finally, 15 mutant strains with a medium MER and 1 mutant strain with a high MER were resulted by using $20 \%$ of $\mathrm{MnCl}_{2}$. No mutants were formed with TAF 23 by using both 10 and $20 \%$ of $\mathrm{MnCl}_{2}$.

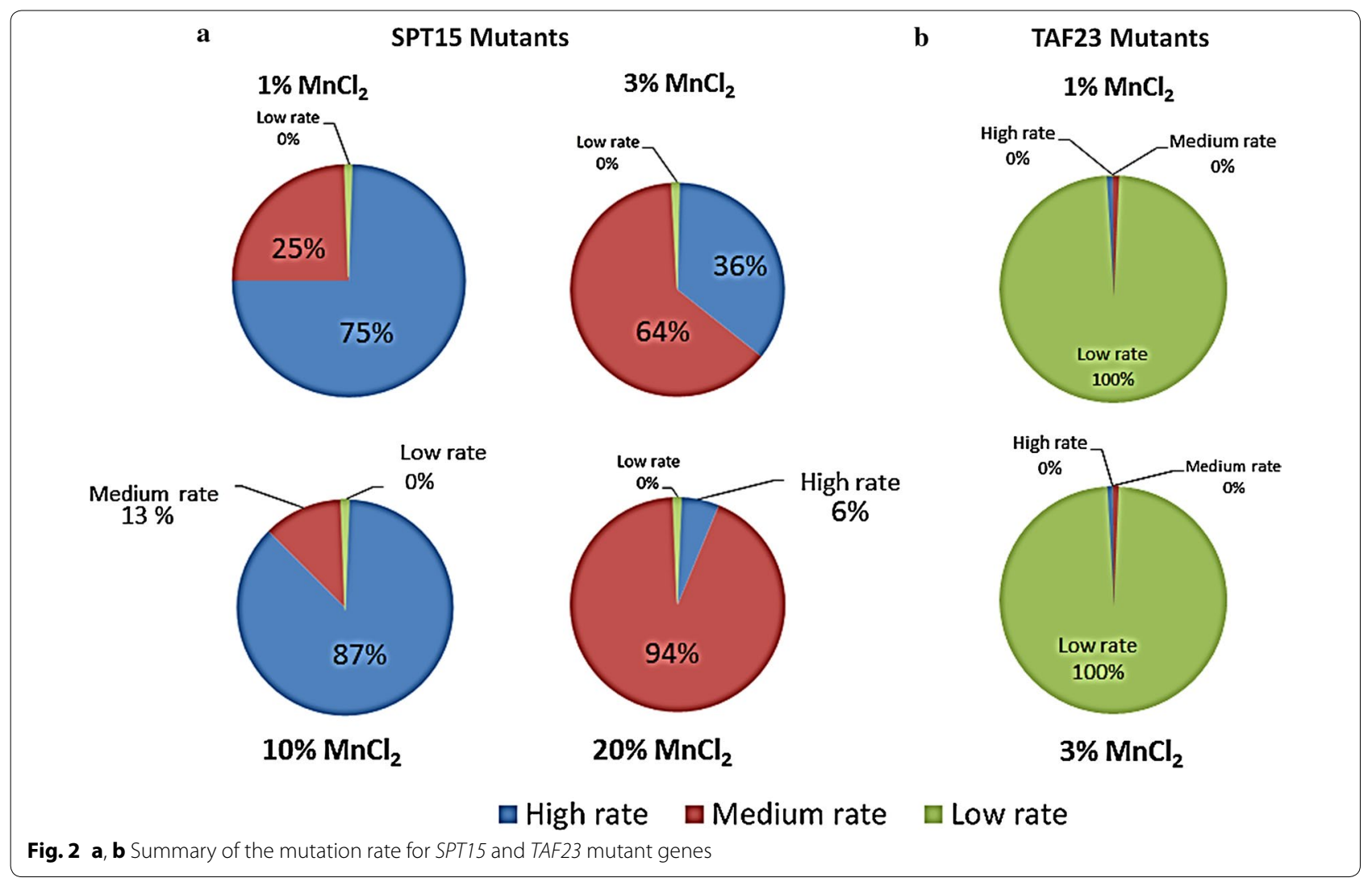


Construction of pYX212-SPT15-Mu and pYX212-TAF23-Mu plasmids

Both SPT15-Mu and TAF23-Mu genes were ligated individually with pYX212 using T4 DNA ligase to construct vector pYX212 with SPT15 and TAF23, respectively. The resultants after ligation processes were named pYX212SPT15-Mu and pYX212-TAF23-Mu, respectively. The gDNA S. cerevisiae R-control was used as a template for PCR reaction. The bands at 723 and 621 bp for SPT15 and TAF23 genes were identified, respectively after the plasmids were digested.

\section{Study of the ethanol tolerance of mutant strains}

Five replicates of TAF23 mutants were checked for the stability of G418 resistance gene, however they were not able to resist and to grow at the concentration $250 \mu \mathrm{g} / \mathrm{mL}$ of G418. In addition, 5 replicates of SPT15 mutations by a total number of 250 were selected, and their stability tests were examined. These mutations were subjected to G418 at two different concentrations, 250 and $350 \mu \mathrm{g} / \mathrm{mL}$, respectively (Walker et al. 2003), to screen the strains harboring stable resistance genes. Subsequently, the Normal PCR was conducted for these strains in order to amplify the successful resistance genes with concentrations of G418 to identify the extent of their activities and the stability for those mutations. Afterthought, we were able to choose the best 102 mutants with SPT15 gene from the total selected 250 mutants. In addition, the total of 14, 24, 37 and 27 mutations were successfully chosen at $1,3,10$ and $20 \%$ of $\mathrm{MnCl}_{2}$.

The ethanol tolerance test was used to investigate 102 selected mutants. After $72 \mathrm{~h}$ of incubation at $30^{\circ} \mathrm{C}$, the colony formation was monitored and recorded. The transported colonies of the new mutants SPT15 gene were compared to R-control strain that showed a slight improvement to form the colony on the media containing 1, 3, 5 and 7\% (v/v) of ETOH. Conversely, the formation and composition of mutant colonies were weak in presence of $10 \% \mathrm{ETOH}$ compared to the low concentrations. Meanwhile, the media containing $15 \%(\mathrm{v} / \mathrm{v})$ of ETOH did not display any growth of colonies (Fig. 3).

\section{Effect of ethanol concentration on the growth rate of mutant strains}

Results confirm of 94 transformants the previously mentioned stability tests, as the better growth rate for these mutants were observed when compared to the R-control strain (Figs. 4, 5). This result indicated that mutations contained SPT15 genes possess the ability to grow coexisting with different concentrations of ethanol more than the R-control strain. Likewise, using a different concentration of $\mathrm{MnCl}_{2}$, the growth was better in the concentration of $3 \%$ followed by 10,20 and $1 \%$, respectively. It was shown that (R-M20C1-P3), (R-M16C4P3), (R-M4C1-P3), (R-M12C4-P3), (R-M18C4-P3) and (R-M5C1-P3) recorded higher growth rates at 3\% of $\mathrm{MnCl}_{2}$. As well, (R-M3C49-P10) and (R-M18C5-P10) were the highest growth mutants with $\mathrm{MnCl}_{2} 10 \%$. Moreover, using $20 \%$ of $\mathrm{MnCl}_{2}$, (R-M17C4-P20) and (R-M9C2$\mathrm{P} 20)$ reported higher growth rates.

In details, mutants of R-M12C4-P3 and R-M18C4P3 recorded a higher growth of values for DCW, which reached to $2.01 \mathrm{~g} / \mathrm{L}$ (DCW) however the R-control recorded $1.39 \mathrm{~g} / \mathrm{L}(\mathrm{DCW})$ at concentration of $1 \%$ ethanol. Moreover, the growth of R-M18C4-P3 mutant recorded the values for (DCW) $1.88 \mathrm{~g} / \mathrm{L}$ at $3 \%$ ethanol; however $1.25 \mathrm{~g} / \mathrm{L}$ was recorded for the R-control. On the other hand, the concentrations 5 and $7 \%$ of ethanol showed better growth rate for all mutants than R-control strain (Figs. 4, 5).

\section{Measurement of the ethanol and glucose yield}

In order to estimate the efficiency of the different mutants for the production of ethanol, HPLC was used in this study. During the aerobic fermentation processes, the production of ethanol in the yeast expressing SPT15 increased more than $60 \%$, moreover the glucose decreased to $0.19 \mathrm{~g} / \mathrm{L}$ compared to the R-control strain. With the addition of $3 \% \mathrm{MnCl}_{2}$, all the mutants showed higher ethanol production from 14.11 to $15.72 \mathrm{~g} / \mathrm{L}$ compared to the R-control which produced $9.8 \mathrm{~g} / \mathrm{L}$, and the other used mutants with 1,10 and $20 \%$ concentrations of $\mathrm{MnCl}_{2}$. The yield of the R-M20C1-P3 mutant strain reported the highest ethanol production $15.72 \mathrm{~g} / \mathrm{L}$ with a reduction in glucose content $0.47 \mathrm{~g} / \mathrm{L}$. The production of ethanol was higher than R-control by using $1 \%$ of $\mathrm{MnCl}_{2}$, however decreased compared to the other mutants.

It is worth mentioning that the SPT15 mutant library showed remarkable growth better than R-control strain in the presence of 1 and 3\% ethanol with $20 \mathrm{~g} / \mathrm{L}$ glucose. Consequently, the stress was increased to 7 and $10 \%$ ethanol in the subsequent serial sub-culturing. The reason for this phenomenon was speculated to be improved growth of all mutants due to their enhanced tolerance to ethanol stress, which was verified through higher mutants of cell density of R-M12C4-P3 and R-M18C4P3 which recorded yield of $2.07 \mathrm{~g} / \mathrm{L}$ (DCW) compare to R-control which was $1.99 \mathrm{~g} / \mathrm{L}$ (DCW). This result was in accordance with previous results reported by Alper et al. (2006). Table 3 further summarizes results after anaerobic fermentation processes to make a comparison of parameters yields between the best mutant strains that obtained and R-control. 

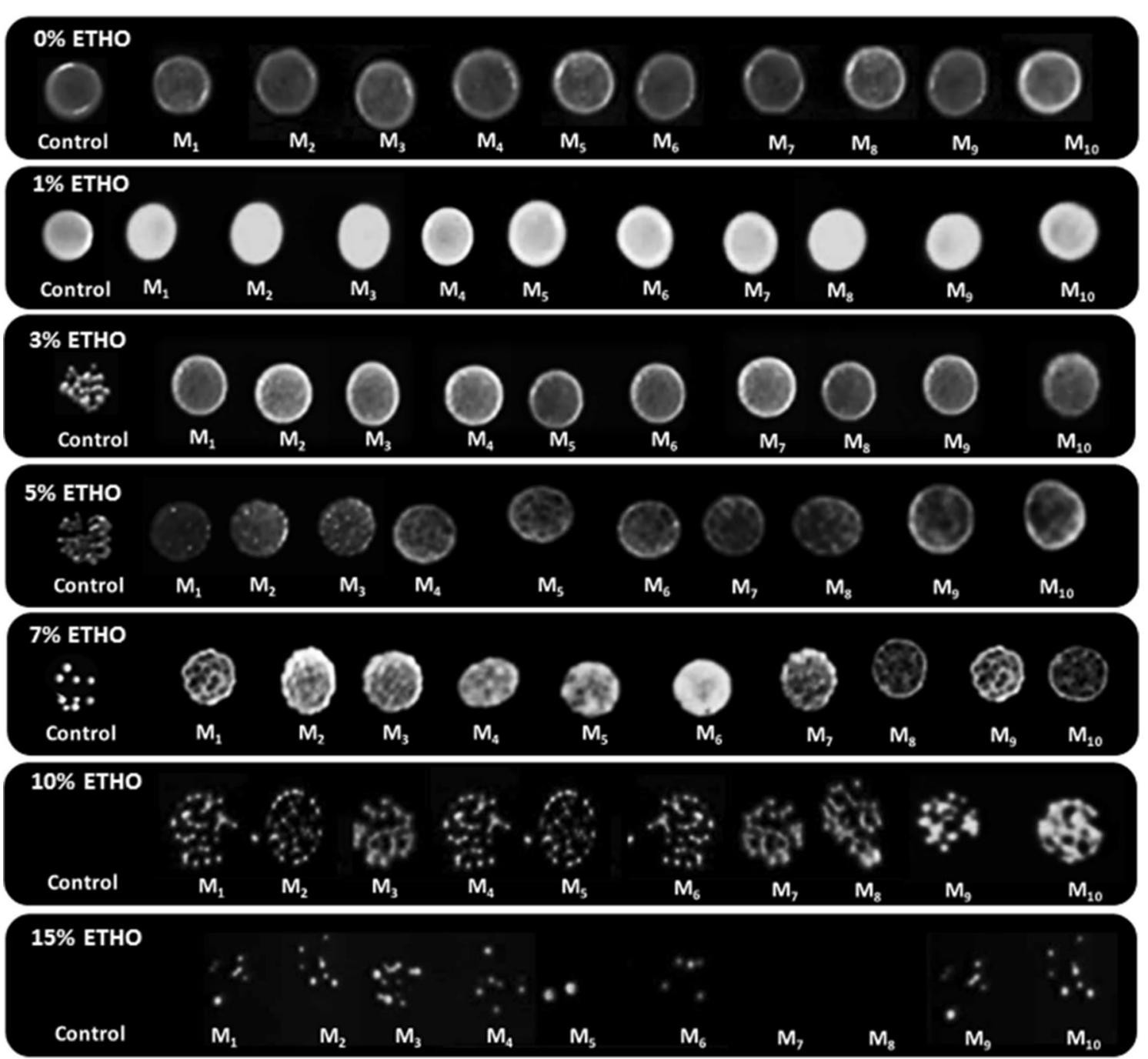

Fig. 3 Susceptibility of ethanol tolerance of $S$. cerevisiae mutant strains with various levels of ethanol concentrations $(0,1,3,5,7,10$ and $15 \%)$ on YPD media containing Kan. M1, M2, M3, M4, M5, M6, M7, M8, M9 and M10 refer to the numbering of mutations colonies; as follows: R-M20C1-P3, R-M16C4-P3, R-M4C1-P3, R-M12C4-P3, R-M18C4-P3, R-M5C1-P3, R-M3C49-P10, R-M18C5-P10, R-M17C4-P20 and R-M9C2-P20, respectively

\section{Discussion}

Up to the present time, the gTME technique has been used for the construction of new mutant; however in our study we processed a new yeast strain for a library of novel mutants by using SPT15 gene. Moreover, the gTME technique has been modified by using $\mathrm{MnCl}_{2}$ instead of the most applied mixture Ep-PCR reaction $\mathrm{MgCl}_{2}$. By using different concentrations of $\mathrm{MnCl}_{2}$ resulted in increasing the error rate throughout DNA synthesis (Pavlov et al. 2004). This modification by using this condition led to an excess of changes from)Adenine to Guanine) and (Thymine to Cytosine), which had been a significant impact on the error rate (Sinha and Haimes 1981).The frequency of mutation in Ep-PCR could be changed by adjusting PCR conditions that provided accessibility in operation for evolution experiments (Wang et al. 2006). The haploid wild-type strains of $S$. cerevisiae (MAT-a) and $(M A T-\alpha)$ have been mated to produce a new diploid strain of $S$. cerevisiae R-control. In the gTME technique, the TBP plays an important role in encoding with SPT15 and TAF23 genes in S. cerevisiae. The theoretical studies have supposed that TAF23 gene is critical to TBP interactions which might due to the presence of TAF23 gene series of helices and linkers (Luhe et al. 2011; Alper et al. 2006; Mal et al. 2004; Gegonne et al. 2001). Consequently, results yielded 6 mutations with $T A F 23-M u$ gene and 50 mutations with SPT15-Mu gene. 

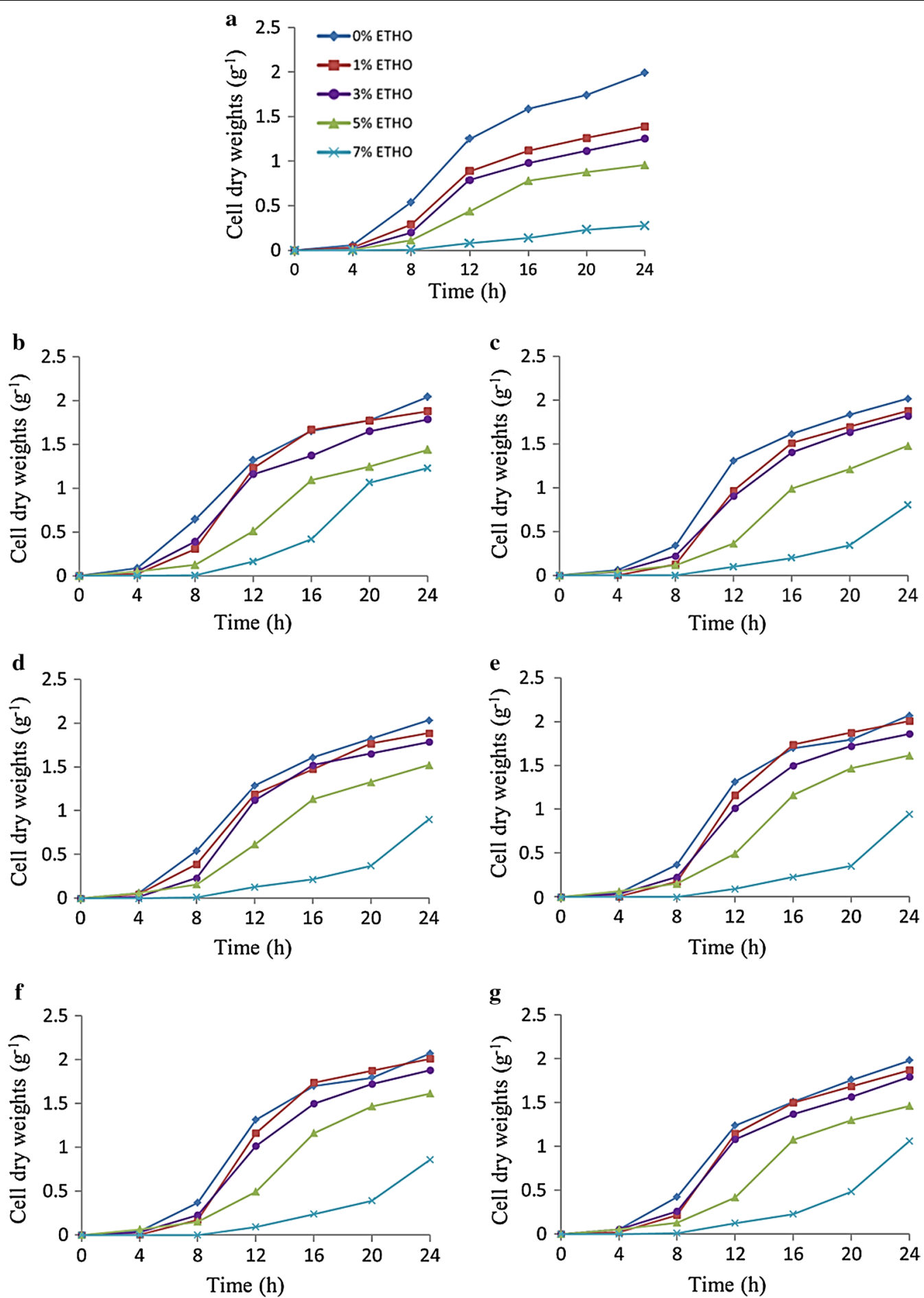

Fig. 4 a Growth curve for the R-control strain and $\mathbf{b}$-g growth curves for the best mutant strains (R-M20C1, R-M16C4, R-M4C1, R-M12C4, R-M18C4 and $\mathrm{R}-\mathrm{M} 5 \mathrm{C}$ 1) obtained by the Ep-PCR reaction by using $3 \% \mathrm{MnCl}_{2}$ concentration, respectively. These strains were inoculated into the YPDT medium

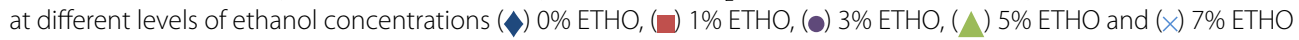



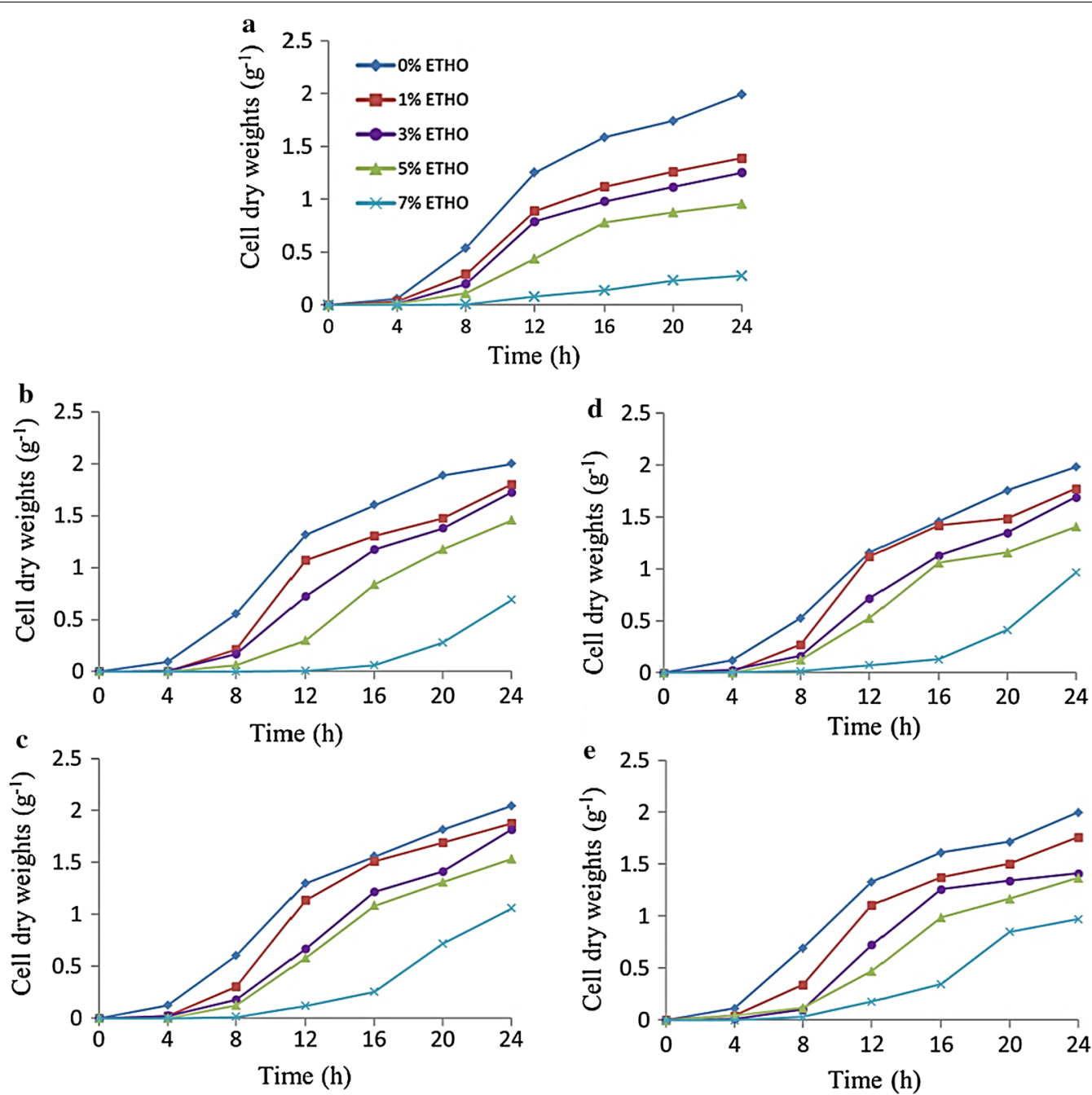

Fig. 5 a Growth curve for the R-control strain and b-e growth curves for the best mutant strains (R-M3C49-P10, R-M18C5-P10, R-M17C4-P20 and R-M9C2-P20) obtained by the Ep-PCR reaction by using 10 and $20 \% \mathrm{MnCl}_{2}$ concentrations, respectively. These strains were inoculated into the YPDT

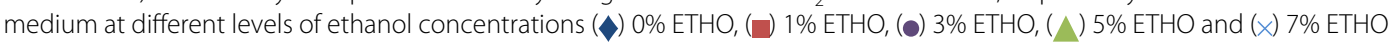

The G418 resistance could simplify the selection of stable transfected cell lines that reflected the characteristics of pYX212-SPT15-Mu and pYX212-TAF23-Mu at the expression of the stabilized genes which were not lost over time. The higher concentrations of G418 $(350 \mu \mathrm{g} /$ $\mathrm{mL}$ ) enhanced the stability of mutant colonies at adverse pressure conditions that produced higher copy of mutations number. These results are similar to the finding reported by Wang et al. (2004).

The influences of ethanol on the growth of the SPT15$M u$ and R-control strains have been investigated through the OD and DCW measurements. They were shown that the growth of all mutants increased gradually with all the concentration of ethanol compare to R-control. Furthermore, SPT15 gene with the addition of thiamin
$200 \mathrm{mg} / \mathrm{L}$ to the medium culture resulted in improving the alcoholic fermentation by enhancing the growth of yeast cells (Kotarska et al. 2006). In the same way, numerous proof-of-concept researchers have confirmed the increasing of cellular tolerances through increasing the production of ethanol and glucose (Liu et al. 2010; Tan et al. 2016). In order to SPT15 as an ensemble, it can provide increased stronger resistance to ethanol and glucose. In addition, SPT15 interacts with TBP to increase its efficient to the SAGA-dependent promoters of many genes (Bhaumik and Green 2002). In conclusion, the genetic results revealed that the gTME technique could be an effective approach for construction of novel mutants under various external stresses. The gTME technique to $S$. cerevisiae has been performed to adapt its attitude 
Table 3 Comparison of parameters yields of the best and highest mutant strains for ethanol production with R-control, during anaerobic fermentation in the presence of $20 \mathrm{~g}$ glucose/L

\begin{tabular}{|c|c|c|c|c|c|c|}
\hline \multirow[t]{2}{*}{ Strains ${ }^{a}$} & \multicolumn{6}{|l|}{ Parameters } \\
\hline & Final DCW (g/L) & Residual GLC (g/L) & Ethanol production $(\mathrm{g} / \mathrm{L})$ & Increase (\%) & YEG ETHO g/GLC g & YEF ETHO $\mathrm{g} / \mathrm{CDW} \mathrm{g}$ \\
\hline R-control & 1.991 & 1.400 & 9.814 & - & 0.527 & 4.927 \\
\hline R-M20C1-P3 & 2.040 & 2.350 & 15.722 & +60.3 & 0.891 & 7.706 \\
\hline R-M16C4-P3 & 2.014 & 1.900 & 15.471 & +57.7 & 0.855 & 7.679 \\
\hline R-M4C1-P3 & 2.032 & 1.900 & 15.470 & +57.7 & 0.855 & 7.616 \\
\hline R-M12C4-P3 & 2.071 & 1.750 & 15.322 & +56.2 & 0.839 & 7.402 \\
\hline R-M18C4-P3 & 2.070 & 2.050 & 15.290 & +55.9 & 0.852 & 7.387 \\
\hline R-M5C1-P3 & 1.981 & 1.700 & 15.211 & +55.1 & 0.831 & 7.680 \\
\hline R-M3C49-P10 & 2.011 & 1.900 & 14.036 & +43.1 & 0.786 & 7.029 \\
\hline R-M18C5-P10 & 2.040 & 2.150 & 14.008 & +42.8 & 0.785 & 6.861 \\
\hline R-M17C4-P20 & 1.984 & 2.050 & 13.486 & +37.5 & 0.756 & 6.811 \\
\hline R-M9C2-P20 & 2.012 & 2.200 & 13.464 & +37.2 & 0.761 & 6.724 \\
\hline
\end{tabular}

P3: $3 \%$ of $\mathrm{MnCl}_{2}, \mathrm{P} 10: 10 \%$ of $\mathrm{MnCl}_{2}$ and $\mathrm{P} 20: 20 \%$ of $\mathrm{MnCl}_{2}$; that were used in the Ep-PCR reaction CDW dry cell weight, GLC glucose, YEG yield of ETHO g/glucose used g, YEF yield of ETHO g/final CDW g

a Indicates to the highest mutant strains for ethanol production

towards higher concentrations of ethanol. All the examined mutants showed much better tolerance toward ethanol stress as compared to the R-control. The mutants resulted by using $3 \%$ of $\mathrm{MnCl}_{2}$ in the process of Ep-PCR recorded the highest ethanol production. In a prospective study, we seek to establish a basis for future industrial applications, through integrating the SPT15 mutant alleles of two new mutant strains into the chromosomes, to enhance ethanol tolerance and survive with high concentration of ethanol in the media.

\begin{abstract}
Abbreviations
gTME: global transcription machinery engineering; E. coll: Escherichia coli; S. cerevisiae: Saccharomyces cerevisiae; VHG: very high gravity; Amp: ampicillin; Kan: kanamycin; G418: glycosid-418 resistance gene; LB: luria-bertani medium; SOB: super optimal broth medium; YPD: bacto-peptone glucose broth medium; TBP: TATA-binding protein; gDNA: genomic DNA; OD: optical density; FDB: fast digest buffer; PCR: polymerase chain reaction; Ep-PCR: error prone polymerase chain reaction; MAT- a: MAT-alpha; HPLC: high performance liquid chromatography analysis; MCS: mutant colonies which were selected; AM: absent mutations; ETHO: ethanol; GLC: glucose; CDW: dry cell weight; YEG: yield of ethanol gram/glucose used gram; YEF: yield of ETHO gram/final CDW gram; ERM: error rate at mutants.
\end{abstract}

\section{Authors' contributions}

AE implemented the conception and design of article besides the acquisition of the data; LZ carried out the critical revision of article for important intellectual content; YL presented the administrative, technical, and logistic support; $S L$ analyzed and interpreted of the data; GS endorsed the final approval of article and funded the work. All authors read and approved the final manuscript.

\section{Author details}

${ }^{1}$ The Key Laboratory of Industrial Biotechnology, Ministry of Education, National Engineering Laboratory for Cereal Fermentation Technology, School of Biotechnology, Jiangnan University, 1800 Lihu Road, Wuxi 214122, Jiangsu, China. ${ }^{2}$ Faculty of Environmental Agricultural Science, El Arish University, El Arish, North Sinai 45526, Egypt.

\section{Acknowledgements}

We thank Zhu Linghuan, Gao Zhi, Hua Li, Wang Junhua, Bemena Leo Duick, Mukama Omar Abdelmoneim Ali, Ahmed Mousa, Sherif Abed, Amr Bakry, Marwan Rashed and Yang Sun for their valuable assistance and continued support during work.

\section{Competing interests}

The authors declare that they have no competing interests.

Availability of data and materials

The data supporting the conclusion of this article is included within the article.

\section{Funding}

This work was funded by Jiangsu Province Science Fund for Distinguished Young Scholars (BK20140002).

\section{Publisher's Note}

Springer Nature remains neutral with regard to jurisdictional claims in published maps and institutional affiliations.

Received: 29 March 2017 Accepted: 4 May 2017

Published online: 02 June 2017

\section{References}

Alper H, Stephanopoulos G (2007) Global transcription machinery engineering: a new approach for improving cellular phenotype. Metab Eng 9:258-267

Alper H, Moxley J, Nevoigt E, Fink GR, Stephanopoulos G (2006) Engineering yeast transcription machinery for improved ethanol tolerance and production. Science 314:1565-1568

Bhaumik SR, Green MR (2002) Differential requirement of SAGA components for recruitment of TATA-box-binding protein to promoters in vivo. Mol Cell Biol 22:7365-7371

Botstein D, Fink GR (1988) Yeast: an experimental organism for modern biology. Science 240:1439-1443

Cadwell RC, Joyce GF (1992) Randomization of genes by PCR mutagenesis. PCR Methods Appl 2:28-33

Cormack BP, Struhl K (1992) The TATA-binding protein is required for transcription by all three nuclear RNA polymerases in yeast cells. Cell 69:685-696 
Drummond DA, Iverson BL, Georgiou G, Arnold FH (2005) Why high-error-rate random mutagenesis libraries are enriched in functional and improved proteins. J Mol Biol 350:806-816

Gegonne A, Weissman JD, Singer DS (2001) TAFII55 binding to TAFII250 inhibits its acetyltransferase activity. Proc Natl Acad Sci 98:12432-12437

Gietz RD (2014) Yeast transformation by the LiAc/SS carrier DNA/PEG method (Clifton, NJ). Methods Mol Biol 1205:1-12

Gietz RD, Woods RA (2006) Yeast transformation by the LiAc/SS carrier DNA/ PEG method (Clifton, NJ). Methods Mol Biol 313:107-120

Green M, Sambrook J (2012) Molecular cloning: a laboratory manual. Cold Spring Harbor Press, Cold Spring Harbor

Guo ZP, Zhang L, Ding ZY, Wang ZX, Shi GY (2011) Improving ethanol productivity by modification of glycolytic redox factor generation in glycerol3-phosphate dehydrogenase mutants of an industrial ethanol yeast. J Ind Microbiol Biotechnol 38:935-943

Hampsey M (1998) Molecular genetics of the RNA polymerase II general transcriptional machinery. Microbiol Mole Biol Rev 62:465-503

Hemsley A, Arnheim N, Toney MD, Cortopassi G, Galas DJ (1989) A simple method for site-directed mutagenesis using the polymerase chain reaction. Nucleic Acids Res 17:6545-6551

Hoffman CS, Winston F (1987) A ten-minute DNA preparation from yeast efficiently releases autonomous plasmids for transformation of Escherichia coli. Gene 57:267-272

Hou L (2009) Novel methods of genome shuffling in Saccharomyces cerevisiae. Biotechnol Lett 31:671-677

Hou LH, Meng M, Guo L, He JY (2015) A comparison of whole cell directed evolution approaches in breeding of industrial strain of Saccharomyces cerevisiae. Biotechnol Lett 37:1393-1398

Jungwoo Y, Ju YB, Young ML, Hyeji K, HyeYM Hyun AK, Su BY, Wankee K, Wonja C (2011) Construction of Saccharomyces cerevisiae strains with enhanced ethanol tolerance by mutagenesis of the TATA-Binding Protein gene and identification of novel genes associated with ethanol tolerance. Biotechnol Bioeng 108:1776-1787

Kasavi C, Eraslan S, Arga KY, Oner ET, Kirdar B (2014) A system based network approach to ethanol tolerance in Saccharomyces cerevisiae. BMC Syst Biol 8:90-104

Kotarska K, Czupryński B, Kłosowski G (2006) Effect of various activators on the course of alcoholic fermentation. J Food Eng 77:965-971

Lanza AM, Alper HS (2011) Global strain engineering by mutant transcription factors. Methods Mol Biol 765:253-274

Lee TI, Young RA (1998) Regulation of gene expression by TBP-associated proteins. Genes Dev 12:1398-1408
Lee KH, Park JH, Kim TY, Kim HU, Lee SY (2007) Systems metabolic engineering of Escherichia coli for L-threonine production. Mol Syst Biol 3:149-160

Lewis BA, Reinberg D (2003) The mediator coactivator complex: functional and physical roles in transcriptional regulation. J Cell Sci 116:3667-3675

Liu H, Yan M, Lai C, Xu L, Ouyang P (2010) gTME for improved xylose fermentation of Saccharomyces cerevisiae. Appl Biochem Biotechnol 160:574-582

Liu SP, Liu RX, El-Rotail AAMM, Ding ZY, Gu ZH, Zhang L, Shi GY (2014) Heterologous pathway for the production of L-phenylglycine from glucose by E. coli. J Biotechnol 186:91-97

Luhe AL, Tan L, Wu J, Zhao H (2011) Increase of ethanol tolerance of Saccharomyces cerevisiae by error-prone whole genome amplification. Biotechnol Lett 33:1007-1011

Mal TK et al (2004) Structural and functional characterization on the interaction of yeast TFIID subunit TAF1 with TATA-binding protein. J Mol Biol 339:681-693

McCullum EO, Williams BA, Zhang J, Chaput JC (2010) Random mutagenesis by error-prone PCR. In vitro mutagenesis protocols, 3rd ed. p 103-109

Pavlov AR, Pavlova NV, Kozyavkin SA, Slesarev Al (2004) Recent developments in the optimization of thermostable DNA polymerases for efficient applications. Trends Biotechnol 22:253-260

Sinha NK, Haimes MD (1981) Molecular mechanisms of substitution mutagenesis. An experimental test of the Watson-Crick and topal-fresco models of base mispairings. J Biol Chem 256:10671-10683

Tan F, Wu B, Dai L, Qin H, Shui Z, Wang J, Zhu Q, Hu G, He M (2016) Using global transcription machinery engineering (gTME) to improve ethanol tolerance of Zymomonas mobilis. Microb Cell Fact 15:1-9

Walker ME, Gardner JM, Vystavelova A, McBryde C, Lopes MD, Jiranek V (2003) Application of the reuseable, KanMX selectable marker to industrial yeast: construction and evaluation of heterothallic wine strains of Saccharomyces cerevisiae, possessing minimal foreign DNA sequences. FEMS Yeast Res 4:339-347

Wang Y, Shi WL, Liu XY, Shen Y, Bao XM, Bai FW, Qu YB (2004) Establishment of a xylose metabolic pathway in an industrial strain of Saccharomyces cerevisiae. Biotechnol Lett 26:885-890

Wang TW, Zhu H, Ma XY, Zhang T, Ma YS, Wei DZ (2006) Mutant library construction in directed molecular evolution. Mol Biotechnol 34:55-68

Xu GQ, Hua Q, Duan NJ, Liu LM, Chen J (2012) Regulation of thiamine synthesis in Saccharomyces cerevisiae for improved pyruvate production. Yeast 29:209-217

Zhang L, Tang Y, Guo ZP, Ding ZY, Shi GY (2011) Improving the ethanol yield by reducing glycerol formation using cofactor regulation in Saccharomyces cerevisiae. Biotechnol Lett 33:1375-1380

\section{Submit your manuscript to a SpringerOpen ${ }^{\odot}$ journal and benefit from:}

- Convenient online submission

- Rigorous peer review

- Immediate publication on acceptance

- Open access: articles freely available online

- High visibility within the field

- Retaining the copyright to your article

Submit your next manuscript at springeropen.com 